\title{
Geriatric dermatosis; the concerns of aging skin.
}

1. MBBS, FCPS (Dermatology) D-DERM (UK)

Associate Professor and Head Dermatology

Karachi Institute of Medical Sciences, Karachi.

2. MBBS, FCPS Medicine

Associate Professor Medicine

Rawal Institute of Health Sciences Islamabad.

3. MBBS, FCPS (Derma) D-DERM (UK)

Assistant Professor \& HOD

Dermatology

Dow University, Ojha Campus Karachi.

4. MBBS, FCPS (Skin)

Associate Professor Dermatology

Hamdard Medical University

Karachi.

5. MBBS, MD (Medicine).

Associate Professor Medicine

Karachi Institute of Medical

Sciences, Karachi.

6. MBBS, FCPS Medicine

Assistant Professor Medicine

Civil Hospital Karachi.

Correspondence Address:

Dr. Furquana Niaz

Associate Professor \& Head of Dermatology

H\# B, 196 Block-15, Gulistan-e-

Jouhar, Karachi.

furquananiaz@hotmail.com

Article received on:

16/08/2019

Accepted for publication:

$25 / 01 / 2020$
Furquana Niaz', Nadia Shams ${ }^{2}$, Sadaf Asim ${ }^{3}$, Humera Maryum ${ }^{4}$, Arshad Ali ${ }^{5}$, Naresh Kumar Seetlani ${ }^{6}$

ABSTRACT... Objectives: To study the cutaneous manifestations in elderly and their association with gender. Study Design: Cross Sectional study. Setting: Sir Syed Hospital Karachi. Period: Jan 2016 to Jan 2018. Material \& Methods: Total 217 geriatric cases (>60 years; both genders) were included from outdoor dermatology clinic. The previous pregnancy, lactation, severe systemic disease and drug induced skin changes were excluded. Results: Among 217 cases, there were 126(58\%) females and 91(42\%) males. Mean age was $69.3+4.99$ years. Wrinkling was seen in $92 \%$, dryness (65\%), skin laxity in $54.8 \%$, xerosis $(43 \%)$, dryness $(65 \%)$, sagging $(46 \%)$, pigmentation $(37 \%)$, eczema $(25 \%)$, sparse hair $(21 \%)$, skin atrophy $(19 \%)$, tinea $(13 \%)$ and LSC $(10 \%)$. While herpes zoster, psoriasis, onychomycosis, tinea corporis , asteotic eczema in $7 \%$. Folliculitis $6 \%$, scabies and bullous pemphigoid seen in $5 \%$, while lichen planus, actinic elastosis, BCC, Prurigo nodularis in $3 \%$. Cellulitis, pediculosis, Seborrheic Dermatitis and contact dermatitis were seen in $2 \%$ followed by $1 \%$ cases of warts, candidiasis, photodermatosis and SCC seen in our study. Folliculitis (6\%) was the most frequent bacterial infection followed by impetigo (0.9\%). Herpes zoster $(6.5 \%)$ was frequent among viral infections followed by warts $(0.9 \%)$ and HSV- $1(0.9 \%)$. Tinea $(13.4 \%)$ was most frequent fungal infection followed by onychomycosis $(7 \%)$ and candidiasis $(0.9 \%)$. Scabies was most common parasitic infection (4.6\%) followed by pediculosis (2.3\%). Eczema seen in $24.8 \%$. The benign dermatosis, Actinic elastosis was frequent (3.2\%), stucco keratosis $4(1.8 \%)$, Keratoacanthoma $(0.9 \%)$. Amongst malignancies, BCC was common (3.2\%), followed by SCC (1.4\%). $5 \%$ Bullous Pemphigoid cases were found. The psychocutaneous disorder included LSC (10\%), prurigo nodularis $(2.8 \%)$ and neurotic excoriation $(0.9 \%)$. Wrinkling, sagging, dryness of skin, actinic keratosis, actinic elastosis was found to be associated with female gender, however cellulitis, squamous cell carcinoma and asteatotic eczema with male gender. Conclusion: Geriatric population is facing multiple dermatological concerns. Contributory factors being the natural aging process, exposure to UV radiation, pathogens, dryness, humidity, temperature and chemical irritants. Female geriatrics are prone to wrinkling, sagging, dryness of skin and male geriatrics to basal cell carcinoma. There is need to address the skin problems in elderly for better quality of life in geriatrics.

Key words: Dermatosis, Geriatric, UV Radiation.

Article Citation: Niaz F, Shams N, Asim S, Maryum H, Ali A, Seetlani NA. Geriatric Dermatosis; the Concerns of Aging Skin. Professional Med J 2020; 27(11):2445-2452. https://doi.org/10.29309/TPMJ/2020.27.11.4050

\section{INTRODUCTION}

Old age has been defined by the United Nations as above 60 years of age to be eligible for old age benefits without any standard criterion. Average life expectancy for global population according the WHO was 71.4 years in 2015 with 79.3 years in USA, 81.2 years in UK and 66.4 years in Pakistan. ${ }^{1}$

With the gradual decline in communicable diseases life expectancy is growing globally, with estimated 524 million people aged 65 or above in 2010 to approximately 1.5 billion in 2050 with the greatest increase in developing countries. ${ }^{2}$

With the increasing age, there is increase in problems of chronic and degenerative diseases i.e. Diabetes, IHD, Cancers, Dementia, etc. This results in significant rise in disease burden. Among the wide array of chronic and degenerative diseases Geriatric dermatoses is an important problem with significant effects on health and 
quality of life. Very little data is available especially in our region to understand the skin problems faced by the elderly and their management.

Aging leads to degeneration of skin that causes metabolic changes that affects the barrier function, sensory perception, wound healing, immune response, DNA repair, elastic tissue and collagen bundles decrease in sweat and sebaceous glands as well as the vascularity, and hyper proliferative disorders. ${ }^{3}$

Aging can occur due to intrinsic factors i.e. normal maturity and extrinsic factors i.e. changes due to UV light exposure, smoking and other environmental factors. ${ }^{4}$ Skin changes that occur with age include xerosis, eczematous reactions, infections, infestations, photodermatoses, neoplasias, immunological disorders, vascular changes, nutritional dermatoses, psychodermatoses and pressure sores etc.

In this study we aim to determine the prevalence of skin diseases in elderly patients, gender preponderance and comparison between infections and non-infectious diseases so that disease trends can be monitored and relevant health care programs can be designed in the future.

\section{MATERIAL \& METHODS}

This descriptive cross sectional study was conducted over 2 years duration at Sir Syed Hospital Karachi from Jan 2016-Jan 2018 after ethical approval. Total 217 patients with age $>60$ years (both the genders) presenting to outdoor dermatology clinic were selected by consecutive sampling. Informed consent was obtained from each patient. Patients having skin changes secondary to past pregnancy, lactation, systemic illness and drugs were also excluded.

A detailed history of cutaneous complaints, present and past medical illness was documented. The complete general physical examination and systemic examination was carried out. Detailed dermatological examination was performed and positive findings were documented in a predesigned proforma.
Complete blood counts, urine routine examination, random blood sugars, chest $x$ ray was advised in each case as per indications. Skin scrapings, nail clipping for fungus, Tzanck smear and skin biopsy were performed as per indication in each case.

Data was analyzed by SPSS-21. Frequencies calculated for qualitative variables (cutaneous manifestations, gender), mean and standard deviation for quantitative variables (age). Chisquare test was applied to study association of skin manifestation with gender with significant $p$-value $<0.05$. Data presented in the form of tbales and bar graph.

\section{RESULTS}

217 patients were enrolled amongst which $126(58 \%)$ were females and $91(42 \%)$ were males. Mean age was 69.3+4.99 (65-91) years, 31(1.4\%) were divorced, 195(90\%) married, 9(04\%) were unmarried and 10 (4.6\%) were widow.

Out of 217 cases, 200 patients were having a wrinkling followed by laxity of skin 119(54.8\%), xerosis 93 (42.9\%), dryness 65\%, sagging 46\%, pigmentation $37 \%$, eczema $25 \%$, sparse hairs $21 \%$, skin atrophy $19 \%$, tinea $13 \%$, LSC $10 \%$, while herpes zoster, psoriasis, onychomycosis, Tinea corporis ,asteotic eczema were seen in $7 \%$, cases.

Folliculitis 6\%, scabies, bullous pemphigoid in $5 \%$, cases while lichen planus, actinic elastosis, $\mathrm{BCC}$, Prurigo nodularis were seen in $3 \%$ cases.

Cellulitis, pediculosis, Seborrheic Dermatitis and contact dermatitis were seen in $2 \%$ followed by $1 \%$ cases of warts, candidiasis, photodermatosis and SCC seen in our study. Among bacterial infection, folliculitis $13(6 \%)$ was the most common infection followed by impetigo 2(0.9\%).

Among viral infection Herpes zoster 14(6.5\%) was the most common dermatosis of the old age group followed by warts $2(0.9 \%)$, HSV 1 $(2(0.9 \%)$ and no cases was found for Molluscum contigiosum. 
In Fungal infections tinea 29(13.4\%) was the most commonly seen followed by onychomycosis $15(7 \%)$, candidiasis $2(0.9 \%)$.

Scabies was the most common parasitic infection $10(4.6 \%)$ followed by pediculosis 5 (2.3\%).

Among papulosquamous lesions eczema was found to be in 54(24.8\%)asteotic eczema $14(6.4 \%)$, Nummular eczema $(0 \%)$, varicose eczema $1.8 \%$ ) were seen.

Among benign Dermatosis, Actinic elastosis was found to be most common dermatosis followed by stucco keratosis $4(1.8 \%)$, Keratoacanthoma $(0.9 \%)$ and no case was reported of bowen,s disease and Lentigo Maligna.

Among malignancy, BCC was the most common Malignancy $7(3.2 \%)$ followed by SCC 3(1.4\%) and no case was found of leukoplakia and Malignan Melanoma(0\%).

Bullous Pemphigoid 11(5\%) cases was found in immunobullous disorder.

Among psychocutaneous disorder LSC 22(10\%) was the most common dermatosis followed by prurigo of nodularis $6(2.8 \%)$, Neurotic excoriation $2(0.9 \%)$ were found. There was no case of delusion of parasitosis in our study.

As per association with gender; wrinkling, sagging, dryness of skin, actinic keratosis, actinic elastosis was found to be associated with female gender, however cellulitis, squamous cell carcinoma and asteatotic eczema was associated with male gender $(p<0.05$; Table-I).

\section{DISCUSSION}

Skin diseases are an important health problem affecting geriatric population. These are common among elderly all over the world. Several epidemiological studies on geriatric dermatosis have been undertaken across the world. Their prevalence varies widely depending on the patient's clinical environment as well as regional and ethinic factors.

Present study has been carried out on 217 elderly Pakistani patients, 126 (58\%) were females and 91 (42\%) were males. It encompassed various types of skin diseases amoung elderly patients attending the skin department.

\section{Cutaneous Manifestations}

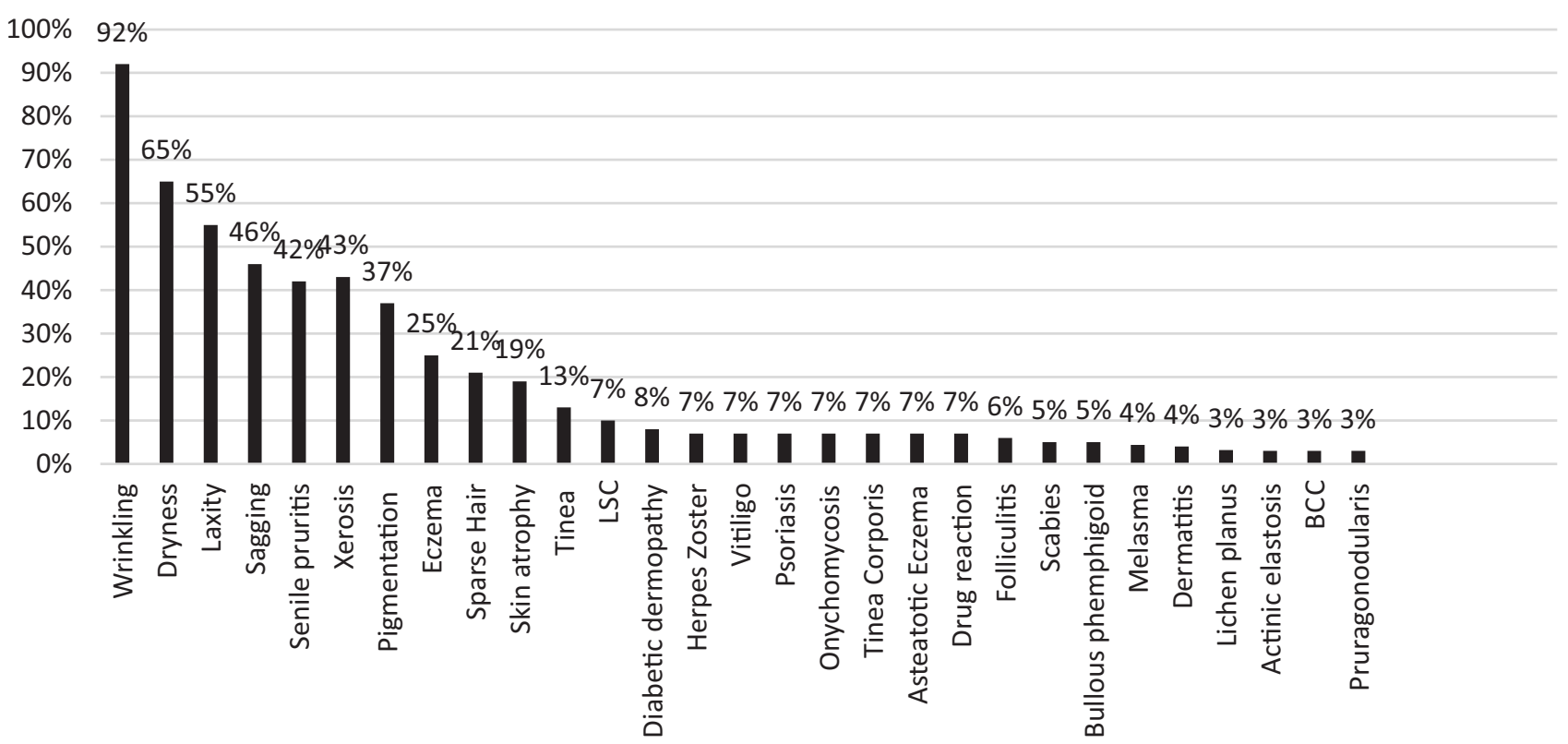

Figure-1. The frequent skin changes observed among geriatric cases $(n=217)$. 


\begin{tabular}{|c|c|c|c|c|c|c|}
\hline \multicolumn{2}{|c|}{$\begin{array}{l}\text { Skin Findings } \\
n(\%) ; n=217\end{array}$} & \multicolumn{2}{|c|}{$\begin{array}{c}\text { Females } \\
n(\%) ; n=126\end{array}$} & \multicolumn{2}{|c|}{$\begin{array}{c}\text { Males } \\
n(\%) ; n=91\end{array}$} & \multirow{2}{*}{$\begin{array}{l}\text { P-Value } \\
\text { 0.003* }\end{array}$} \\
\hline Wrinkling & $200(92.2 \%)$ & $\begin{array}{c}\text { Yes } \\
122(97 \%)\end{array}$ & $\begin{array}{c}\text { No } \\
4(3 \%)\end{array}$ & $\begin{array}{c}\text { Yes } \\
78(86 \%)\end{array}$ & \begin{tabular}{c|} 
No \\
$13(14 \%)$
\end{tabular} & \\
\hline Laxity & $119(54.8 \%)$ & $73(58 \%)$ & $53(42 \%)$ & $46(38.7 \%)$ & $45(46 \%)$ & 0.281 \\
\hline Yellow Discolor. & $4(1.8 \%)$ & $0(0 \%)$ & $126(100 \%)$ & $4(4.4 \%)$ & $87(95.6 \%)$ & 0.018 \\
\hline Skin Atrophy & $42(19.4 \%)$ & $29(23 \%)$ & $101(80 \%)$ & $17(18.6 \%)$ & $74(81 \%)$ & 0.831 \\
\hline Dryness & $140(64.5 \%)$ & $88(70 \%)$ & $38(30 \%)$ & $52(57 \%)$ & $39(43 \%)$ & $0.05^{\star}$ \\
\hline Sparse Hair & $45(20.7 \%)$ & $30(24 \%)$ & $96(76 \%)$ & $15(16.5 \%)$ & $76(83.5 \%)$ & 0.189 \\
\hline Androgenic Allopaecia & ---- - & --- & ---- & $33(36 \%)$ & $58(64 \%)$ & ---- \\
\hline \multicolumn{7}{|c|}{ Eczema } \\
\hline Eczema & $54(24.8 \%)$ & $28(22 \%)$ & $98(78 \%)$ & $26(28.6 \%)$ & $65(71.4 \%)$ & 0.286 \\
\hline \multicolumn{7}{|c|}{ Dermatitis } \\
\hline Seborheic dermatitis & $5(2.3 \%)$ & $3(2.4 \%)$ & $123(97.6 \%)$ & $292.2 \%)$ & $89(97.8 \%)$ & 0.929 \\
\hline Contact dermatitis & $4(1.8 \%)$ & $3(2.4 \%)$ & $123(97.6 \%)$ & $1(1 \%)$ & $90(99 \%)$ & 0.488 \\
\hline \multicolumn{7}{|c|}{ Sunlight Exposure } \\
\hline Photodermatosis & $2(0.9 \%)$ & $2(1.6 \%)$ & $124(98.4 \%)$ & $0(0 \%)$ & $91(100 \%)$ & 0.227 \\
\hline Actinic keratosis & $2(0.9 \%)$ & $7(5.6 \%)$ & $119(94.4 \%)$ & $0(0 \%)$ & $91(100 \%)$ & $0.022^{*}$ \\
\hline \multicolumn{7}{|c|}{ Benign Conditions } \\
\hline Bowens disease & $0(0 \%)$ & $0(0 \%)$ & $0(0 \%)$ & $0(0 \%)$ & $0(0 \%)$ & - \\
\hline Actinic elastosis & $7(3.2 \%)$ & $7(5.6 \%)$ & $119(94.4 \%)$ & $0(0 \%)$ & $91(100 \%)$ & $0.022^{\star}$ \\
\hline Stucco keratosis & $4(1.8 \%)$ & $2(1.6 \%)$ & $124(98.4 \%)$ & $2(2.2 \%)$ & 89(97.8\%) & 0.741 \\
\hline KA & $2(0.9 \%)$ & $0(0 \%)$ & $126(100 \%)$ & $2(2.2 \%)$ & $89(97.8 \%)$ & 0.095 \\
\hline Connective tissue disorders & $2(0.9 \%)$ & $2(1.6 \%)$ & $124(98.4 \%)$ & $0(0 \%)$ & $91(100 \%)$ & 0.761 \\
\hline \multicolumn{7}{|c|}{ Psycho-Cutaneous Disorders } \\
\hline LSC & $22(10 \%)$ & $14(11 \%)$ & $112(89 \%)$ & $8(9 \%)$ & $83(91 \%)$ & 0.576 \\
\hline Neurotic excoriations & $2(0.9 \%)$ & $2(1.6 \%)$ & $124(98.4 \%)$ & $0(0 \%)$ & $91(100 \%)$ & 0.227 \\
\hline Delusion of parasitosis & $0(0 \%)$ & $0(0 \%)$ & $0(0 \%)$ & $0(0 \%)$ & $0(0 \%)$ & - \\
\hline Prurigo nodularis & $6(2.8 \%)$ & $2(1.6 \%)$ & $124(98.4 \%)$ & $4(4.4 \%)$ & $87(95.6 \%)$ & 0.213 \\
\hline Pigmentation Disorders & $81(37 \%)$ & $49(39 \%)$ & $77(61 \%)$ & $32(39.5 \%)$ & $59(43.4 \%)$ & 0.576 \\
\hline Vitiligo & $16(7 \%)$ & $6(4.8)$ & $120(95.2 \%)$ & $10(11 \%)$ & $81(89 \%)$ & 0.083 \\
\hline Melasma & $10(4.6 \%)$ & $8(6.3 \%)$ & 118(93.7\%) & $3(3.3 \%)$ & $88(96.7 \%)$ & 1.023 \\
\hline Ashy dermatosis & $2(0.9 \%)$ & $1(0.8 \%)$ & $125(99.2 \%)$ & $1(1 \%)$ & $90(99 \%)$ & 0.816 \\
\hline \multicolumn{7}{|c|}{ Others } \\
\hline Psoriasis & $15(7 \%)$ & $10(7.9 \%)$ & $116(92.1 \%)$ & $5(5.5 \%)$ & $86(94.5 \%)$ & 0.484 \\
\hline Lichen planus & $7(3.2 \%)$ & $4(3.17)$ & $122(96.8 \%)$ & $3(3.3)$ & $88(96.7 \%)$ & 0.959 \\
\hline Keloid & $5(2.3 \%)$ & $3(2.4 \%)$ & $123(97.6 \%)$ & $2(2.2 \%)$ & $89(98 \%)$ & 0.929 \\
\hline Urticaria & $5(2.3 \%)$ & $2(1.6 \%)$ & $124(98.4 \%)$ & $3(3.3 \%)$ & $88(96.7 \%)$ & 0.407 \\
\hline Insect bite & $2(0.9 \%)$ & $0(0 \%)$ & $126(100 \%)$ & $2(2.2 \%)$ & $89(9.8 \%)$ & 0.382 \\
\hline Drug reaction & $15(7 \%)$ & $11(8.7 \%)$ & $115(91.3 \%)$ & $4(4.4 \%)$ & $87(95.6 \%)$ & 0.214 \\
\hline Erythema multiforme & $5(2.3 \%)$ & $3(2.4 \%)$ & $123(97.6 \%)$ & $2(2.2 \%)$ & $89(9.8 \%)$ & 0.929 \\
\hline Erythema nodosum & $4(1.8 \%)$ & $3(2.4 \%)$ & $123(97.6 \%)$ & $1(1 \%)$ & $90(99 \%)$ & 0.488 \\
\hline Diabetic dermopathy & $18(8 \%)$ & $10(7.9 \%)$ & $116(94.3 \%)$ & $8(8.8 \%)$ & $83(91.2 \%)$ & 0.821 \\
\hline
\end{tabular}




\begin{tabular}{|c|c|c|c|c|c|c|}
\hline \multirow{2}{*}{\multicolumn{2}{|c|}{$\begin{array}{l}\text { Skin Findings } \\
n(\%) ; n=217\end{array}$}} & \multicolumn{2}{|c|}{$\begin{array}{c}\text { Females } \\
n(\%) ; n=126\end{array}$} & \multicolumn{2}{|c|}{$\begin{array}{c}\text { Males } \\
n(\%) ; n=91\end{array}$} & \multirow[t]{2}{*}{ P-Value } \\
\hline & & Yes & No & Yes & No & \\
\hline \multicolumn{7}{|c|}{ Bacterial Infections } \\
\hline Impetigo & $2(0.9 \%)$ & $2(1.6 \%)$ & $124(98.4 \%)$ & $0(0 \%)$ & $91(100 \%)$ & 0.227 \\
\hline Foliculitis & $13(6 \%)$ & $7(5.6 \%)$ & $119(94.4)$ & $6(6.6 \%)$ & $85(93.4 \%)$ & 0.751 \\
\hline Cellulitus & $5(2.3 \%)$ & $0(0 \%)$ & $126(100 \%)$ & $5(5.5 \%)$ & $86(94.5 \%)$ & $0.008^{*}$ \\
\hline Erysepelas & $0(0 \%)$ & $0(0 \%)$ & $0(0 \%)$ & $0(0 \%)$ & $0(0 \%)$ & - \\
\hline \multicolumn{7}{|c|}{ Viral Infections } \\
\hline Herpes zoster & $14(6.5 \%)$ & $9(7 \%)$ & $117(93 \%)$ & $5(5.5 \%)$ & $86(94.5 \%)$ & 0.626 \\
\hline HSV1 & $2(0.9 \%)$ & $2(1.6 \%)$ & $124(98.4 \%)$ & $0(0 \%)$ & $91(100 \%)$ & 0.227 \\
\hline MC & $0(0 \%)$ & $0(0 \%)$ & $0(0 \%)$ & $0(0 \%)$ & $0(0 \%)$ & - \\
\hline Common warts & $2(0.9 \%)$ & $0(0 \%)$ & $126(100 \%)$ & $2(2.2 \%)$ & $89(97.8 \%)$ & 0.095 \\
\hline \multicolumn{7}{|c|}{ Fungal Infections } \\
\hline Onychomycosis & $15(7 \%)$ & $9(7 \%)$ & $117(93 \%)$ & $6(6.6 \%)$ & $86(93.4 \%)$ & 0.875 \\
\hline Candidiasis & $2(0.9 \%)$ & $2(1.6 \%)$ & $124(98.4 \%)$ & $0(0 \%)$ & $91(100 \%)$ & 0.227 \\
\hline Tinea Corporis & $16(7.4 \%)$ & $7(5.6 \%)$ & $119(94.4 \%)$ & $9(10 \%)$ & $82(90 \%)$ & 0.228 \\
\hline Tinea & $29(13.4 \%)$ & $18(14 \%)$ & $108(86 \%)$ & $11(12 \%)$ & $80(88 \%)$ & 0.639 \\
\hline \multicolumn{7}{|c|}{ Parasitic Infections } \\
\hline Pediculosis & $5(2.3 \%)$ & $5(4 \%)$ & $121(96 \%)$ & $0(0 \%)$ & $91(100 \%)$ & 0.055 \\
\hline Scabies & $10(4.6 \%)$ & $5(4 \%)$ & $121(96 \%)$ & $5(5.5 \%)$ & $86(94.5 \%)$ & 0.597 \\
\hline
\end{tabular}

Table-II. The various skin infections among geriatric cases in association with gender $(n=217)$.

Over the one year study period, wrinkling was the most commonly observed condition in geriatrics. Tindall and smith $^{5}$, Grover \& Naura simhalu ${ }^{6}$, Beauregard \& Gilchrest ${ }^{7}$, and Durai, Thappa et $\mathrm{al}^{8}$ have reported wrinkling in 94\%, 95.5\%, 95.6\% and $99 \%$ patients respectively which coincide with the results of our study. Most of the wrinkling seen in our study was on sunexposed areas i.e. the face, neck, forearm and dorsum of hands in the form of glyphic wrinkles. Slightly lower incidence of wrinkling in the study may be because of increased tolerance of racially pigmented skin to sunlight. ${ }^{9}$

Wrinkling was followed by dryness 140(64.5\%), laxity $119(54.8 \%)$, xerosis $93(42.9 \%)$ and pruritis $90(41.5 \%)$. Pruritis was the $5^{\text {th }}$ most common symptom seen in the study. Leena Raveendra seen pruritis was the commonest symptom $88(44 \%)$ in his study. ${ }^{6}$ Patanage and Fernandez ${ }^{10}$ found pruritis in $78.55 \%$ of patients. In all studies, pruritis has been the commonest complaint noted varying from $11.5 \%$ to $49.6 \% .^{8,9,11,12}$
Wrinkling, sagging and dryness of skin was associated with female gender and yellow discolouration with male gender $(p<0.05)$. The possible reason for association of wrinkling and skin dryness with female gender could be because of comaparatively fewer sweat glands, less sebum secretion, thinner skin, less collagen. Also the post-menopausal hormonal changes are also additional contributory factors. Similarly the sagging of skin in females can be explained by thinner skin and lesser collagen content in females as compared to males.

In evaluating the older people's skin, the greatest problem is to set a demarcation between physiological and pathological findingsl. Several geriatric skin changes and lesions are normal physiological findings except occasional pathological changes that vary in degree and number.

In this study xerosis, wrinkling and atrophy are being considered physiological. Xerosis was the most common physiological change seen in the 
present study i.e. $93 \%$ of patients that coincides with the results seen by Leena Reveendre. ${ }^{9}$ Xerosis was noted in $7 \%^{9,10}, 12.5 \%^{9,13}, 77 \%^{5,9}$, $85 \%^{7,9}$ and $99.8 \%^{6,8,9,14}$ of patients in various studies. The higher incidence of xerosis in this study is comparable to few studies..$^{5,7}$ However, the higher incidence of xerosis could be attributed to less use of emollients and usage of harsh soaps by the subjects of the study who mostly belonged to rural areas.

Infectious conditions occur as a result of a combination of diminished immunity and predisposing medical conditions like diabetes mellitus or other systemic diseases. Also the neglect, reduced local skin care and poor personal hygiene could be contributing factors. Our study showed decreased ranges of infection ( $7.4 \%$ vs $33.8 \%)$. $^{5,6,4,15,16,17}$

In this study. the fungal Infections were seen in $28.5 \%$ cases. Among these, tinea infections were seen in $13.4 \%$, while tinea corporis was seen in $7.4 \%$, followed by onychomycosis $(7 \%)$ followed by candidiasis $(2 \%)$.

Fungal infections $28.5 \%$ were higher than in Singapore(4.5\%), croatian (6.8\%), Tunisian (16\%) and Indian (17.5\%) $)^{7,9,17,18,19}$ lower than in Taiwan (38\%). ${ }^{15}$ Fungal infections were mainly represented by tinea corporis $7.4 \%$ and onychomycosis $7 \%$. The high prevalence of mycosis in our study may be explained by our hot humid climatic conditions. Frequent washing (ablusion) for praying without subsequent drying predisposes to tinea which often serves as a primary source of infection that can spread to nails also. ${ }^{3,4}$

Frequency of viral infections in our patients was $6.5 \%$. In indian and Singaporean studies: $5 \%$ and $3.4 \%$ but less which was reported in Tunisian $6.8 \%$,6,16,19 and in Taiwan data (12.3\%) $)^{4,19}$ respectively. Herpes zoster incidence is higher in elderly, it was mostly Diagnosed viral illness in our elderly $6.5 \%$, our prevalence is far away from that reported by Chopra A in an indian study $(0.9 \%)^{4,17}$ Certain risk factors, most likely reduced cell mediated immunity with advancing age, may reactivate varicella zoster virus..$^{3,4}$
Six percent of elderly patients had folliculitis among bacterial infections: This is higher than indian data (4.5\%) , Tunisian (8.7\%) ${ }^{4,6,17,19}$ Cellulitis was the least common bacterial infection was seen in our study i.e. $2.3 \%$, that is contrary to literature. ${ }^{3}$ The frequency of cellulitis could be explained by presence of predisposiong factors as tinea pedis, dry skin, diabetes mellitus and compromised blood circulation in peripheries among elderly. Only cellulitis was found to be associated with male gender $(p=0.008)$ and there was no association of any other infection with gender.

Scabies is important parasitic infection in elderly. It was diagnosed in $4.6 \%$ of our patients which is reported in Singapore by Yap KB et al. ${ }^{4,16}$

Eczema was found in $1 / 4$ th of cases i.e. $24.8 \%$. Our results agree with the figures reported in literature (2.8\%-24.7\%). 3,7,17,18 Contact Dermatitis has been reported to occur in lower as $1.8 \%$ of the elderly population and include both Allergic contact Dermatitis and Irritant Contact Dermatitis. The prevalence of contact Dermatitis may be due to self medication, i.e. by application of various topical medications as antimicrobial and analgesics. Also some traditionally used agents including plant productes, herbals ,oils, balms in addiction to common allergens as dyes, rubber, alkaline, soaps, detergents are the main culprits in cases of Allergic contact dermatitis. ${ }^{4}$ Astatotic eczema was associated with male gender $(p=0.024)$

Older patients, who often have vascular abnormality associated with atherosclerosis and diabetes mellitus are prone to develop stasis Dermatitis. This study had $1.8 \%$ of patients had stasis eczema that was lower than india and Turkish data. ${ }^{4,6,7,18}$ Seborrheic Dermatitis is commonly seen in the elderly, our frequency was lower $(2.3 \%)$ than reported figures in Turkey and India (i.e. 93.9\% and 16.5\%).

Psoriasis is a chronic life long disease and the frequency of psoriasis in elderly varies in different studies. Seven percent of our patients had psoriasis and a frequency of $3 \%$ to $12.5 \%$ has 
been reported in Croatia and India. 4,6,15,16,17

The $7 \%$ incidence of vitiligo in this study was comparable to Sahoo et al's findings (5\%)..$^{20}$ This is higher than western studies results (1.4\%)..$^{3,21}$ But lower than reports of Patanage (19\%). ${ }^{10}$ This variation could be due to ethinic and racial factors. A psychosomatic background observed nearly $13.8 \%$, among them Lichen simpex chronicus (LSC) 10\% was the most common, followed by neurotic excoriation (0.9\%), delusion of parasitosis $(0 \%)$ and prurigo nodularis $(2.8 \%)$. Our figures are less than what has been observed in rest of the studies. ${ }^{4,17}$

Bullous pemphigoid was diagnosed in 5\% which is higher than the reported figure in literature (i.e. $0.5-1.8 \%) .4,6,17$ An altered immunological reactivity of skin is likely to be involved. Collegen vascular disease were observed in $0.9 \%$ which was lower than the indian data (3.5\%). ${ }^{4,6}$

Common types of beningn tumours include Bowen's disease, actinic elastosis, stucco keratosis, keratoacanthoma and lentigo maligna. Our study trailed the reported prevalence rates $1.8 \%$ Vs. $24.2-88 \%, 4,5,7,17,19$ the Croatian results $(18.98 \%)$ were higher than our study. ${ }^{4,15}$ The differences underscore the ehinic and regional variations between different study populations. Actinic keratosis is common in fair skin individuals that are chronically exposed to the sun (22$25 \%$ ). ${ }^{4,15,19,21}$ Our prevalence was only $3.2 \%$ as the majority of our population were not fair skinned. Actinic keratosis was more associated with female $(p=0.022)$.

The basal cell carcinoma (BCC) and squamous cell carcinoma (SCC) are by far the most common malignancies in west. In our study tumours were seen in $4.6 \%$ of geriatrics. The BCC $(3.2 \%)$ was the most common malignancy that is contrary to Taiwan and Indian studies results.,12,22 Ultravoilet radiation is the major etilogical factor for development of skin cancer. ${ }^{23}$ Hence skin cancer is often found with a background of sun rays induced damage. In addition, the carcinogenic agents such as tobacco also contribute to the pathogenesis of malignancy. The benighn tumour actinic elastosis was more frequent in females. The Basal call carcinoma was found to be associated with males gender $(p=0.040)$; this can be explained by possibly higher exposure to UV radiation in males as per the social norms, earning responsibility and increased outdoor activity in males.

There is limited regional data addressing geriatric dermatological issues. This study provides us information about the physiological and pathological concerns of aging skin. In view of certain limitations of study (i.e sampling technique sample size), authors recommend careful interpretation of data and further regional studies in this context with better sample size, along with evaluation of co-morbids, profession, socioecomonomic class and sun exposure. The results of this study will help us better understand and manage the dermatological concerns of geriatrics in view of additional factors in geriatrics that differ from the youthful skin.

\section{CONCLUSION}

The geriatric population facing several skin concerns. Factors such as exposure to uv radiations, pathogens, dryness, humidity, temperature and chemical pathogens apart from natural ageing process is also contributory to early skin aging process which may lead to Dermatological conditions in old age. Female geriatrics are prone to wrinkling, sagging, dryness of skin and male geriatrics to basal cell carcinoma. There is need to address the skin problems In the elderly with the background of the physiological changes in skin for better quality of life in geriatrics.

\section{DISCLOSURE}

There was no conflict of interest of any authors. Copyright $@ 25$ Jan, 2020.

\section{REFERENCES}

1. World Health Organization. World health statistics 2016: Monitoring health for the SDGs, sustainable development goals. Geneva: WHO; 2016.

2. World Health Organization. Global health and aging. Geneva: WHO Press; 2011 
3. Worley CA. Aging skin and wound healing. Dermatology nursing. 2006 Jun 1;18(3):265.

4. Elfaituri SS. Geriatric dermatoses in Benghazi, Libya. J Turk Acad Dermatol. 2015;9(3):1-11. DOI: 10.6003/ jtad.1593a1

5. Tindal JP, Smith JG. Skin lesions of the aged and their association with the internal changes. JAMA.1963: 186:1039-42.

6. Grover S, Narasimhalu C. A clinical study of skin changes in geriatric population. Indian journal of Dermatol Venereol Leprol. 2009: 75:305-6.

7. Beauregard S, Gilchrest BA. A survey of skin problemsand skin care regimens in the elderly. Arch Dermatol.1987;123:1638-43.

8. Durai PC, Thappa DM, Kumari R, Malathi M. Aging in elderly: Chronological verses photoaging. Indian j Dermatol. 2012: 57:343-52.

9. Raveendra L. A clinical study of geriatric dermatoses. Our Dermatology Online/Nasza Dermatologia Online. 2014 Jul 1;5(3).

10. Patanage verses Fernandez RJ. A study of geriatric dermatoses. Indian journal of Dermatol venerol leprol.1995:61:206-8.

11. Yalciin B,Tamer E,Toy GG, Ozais P, Haryan M, Alli N. The prevalence of skin diseases in the elderly: Analysis of $\mathbf{4 0 9 9}$ in geriatric patients. Int journal of Dermatol, 2006,45:672-6.

12. Liao YH, chen KH, Tseng MP, Sun CC. Pattern of skin diseases in geriatric patients in Taiwan. Dermatology. 2001:203:308-13
13. Sahoo A, Singh PC, Pattnaik S, Panigrahi RK. Geriatric dermatoses in Southern Orissa. Indian j Dermatol. 2000,45:66-8.

14. Verbov J. Skin problems in the older patients. Practioner.1975:215:612-22.

15. Cvitanovic et al:. Skin disease in a geriatric patients group in outpatient Dermatologic clinic Karlovac, Croatia. Coll Antropol. 34 (2010)suppl. 2: 247-251

16. Yap KB, Siew MG,Goh CL. Pattern of skin diseases in the elderly seen at the national skin center. Singapore Med J 1994:35:147-150.

17. Chopra A. Skin diseases in the elderly. Indian $J$ Dermatol Venerol leprol 1999:65:245-246.

18. Souissi A,Zeglaoui $F$, el Fekih etal. Skin diseases in the elderly: A multicenter Tunisian study. Ann Dermatol Venereol 2006:133:231-234.

19. Smith DR, Leggat PA. Prevelence of skin disease among elderly in different clinical environments. Australasian J Ageing 2005: 24:71-76.

20. Sahoo A, Singh PC, Pattnaik S, Panigrahi RK. Geriatric dermatoses in Southern Orissa. Indian j Dermatol. 2000,45:66-8.

21. Chan HL. The skin in elderly, Singapore Med J 1994:35:141-142.

22. Chang IJ, Chen FI, Lee CC, et al. Dermatological out patient services utilization among elderly in Taiwan: A nation profile. Dermatologica sinica 2006:24:171e180.

23. Situm M, Buljan M, Bulat V, Mihic LL, Bolanca Z, Simic D. UV Radiation and basal cell carcinoma. Coll. Antropol. 2008; 32(2): 167-170.

\begin{tabular}{|c|l|l|l|}
\hline \multicolumn{3}{|c|}{ AUTHORSHIP AND CONTRIBUTION DECLARATION } \\
\hline Sr. \# & Author(s) Full Name & \multicolumn{1}{|c|}{ Contribution to the paper } & Author(s) Signature \\
\hline 1 & Furquana Niaz & $\begin{array}{l}\text { Gave the idea about study, Data collection } \\
\text { was done, Wrote introduction, material } \\
\text { methods and discussion, Sent to the } \\
\text { journal. } \\
\text { Study design was agreed, Data collection } \\
\text { was done, Did statistical analysis, Wrote } \\
\text { resutls, Correction in articles. } \\
\text { Study design was agreed, Data collection } \\
\text { was done. } \\
\text { Study design was agreed, Data collection } \\
\text { was done. }\end{array}$ \\
\hline 3 & Nadia Shams & $\begin{array}{l}\text { Sadaf Asim } \\
\text { Study design was agreed, Data collection } \\
\text { was done. } \\
\text { Study design was agreed, Data collection } \\
\text { was done. }\end{array}$ \\
\hline 6 & Arshad Ali & Naresh Kumar Seetlani \\
\hline
\end{tabular}

